\title{
Both high and low spatial frequencies are critical for visual consciousness in autism: Evidence of an emotional attentional blink paradigm.
}

Adeline Lacroix ( $\nabla$ adeline.lacroix@univ-grenoble-alpes.fr)

Laboratoire de Psychologie et Neurocognition (CNRS/UGA) https://orcid.org/0000-0001-6990-5949

Marie Gomot

UMR1253, Imagerie et Cerveau, Université de Tours, Inserm, 37000 Tours

Margot Fombonne

Univ. Grenoble Alpes, Univ. Savoie Mont Blanc, CNRS, LPNC, 38000, Grenoble

Mickaël J. R. Perrier

Institue for Transport Studies, University of Leeds, LS2 9JT

\section{Carole Peyrin}

Univ.Grenoble Alpes, Univ. Savoie Mont Blanc, CNRS, LPNC, 38000, Grenoble

Nicolas Vermeulen

UCLouvain, Psychological Sciences Research Institute, Louvain-la-Neuve and FNRS-FRS, Brussels

Gewnhi Park

Department of Psychology, Hope College

Frédéric Dutheil

Université Clermont Auvergne, CNRS, LaPSCo, CHU Clermont Ferrand, WittyFit, F-63000, Clermont-

Ferrand

Martial Mermillod

Univ. Grenoble Alpes, Univ. Savoie Mont Blanc, CNRS, LPNC, 38000, Grenoble

\section{Research Article}

Keywords: autism, spatial frequencies, visual consciousness, attentional blink, face processing

Posted Date: June 8th, 2021

DOl: https://doi.org/10.21203/rs.3.rs-16508/v2

License: (c) (1) This work is licensed under a Creative Commons Attribution 4.0 International License.

Read Full License 
Both high and low spatial frequencies are critical for visual consciousness in autism: Evidence of an emotional attentional blink paradigm.

Adeline Lacroix ${ }^{\mathrm{a}}$, Marie Gomot ${ }^{\mathrm{b}}$, Gewnhi Park ${ }^{\mathrm{c}}$, Margot Fombonne ${ }^{\mathrm{a}}$, Mickaël J. R. Perrier ${ }^{\mathrm{a}, \mathrm{d}}$, Carole Peyrin ${ }^{\mathrm{a}}$, Nicolas Vermeulen ${ }^{\mathrm{e}, \mathrm{f}}$, Frédéric Dutheilg, and Martial Mermillod ${ }^{\mathrm{a}}$

a Univ. Grenoble Alpes, Univ. Savoie Mont Blanc, CNRS, LPNC, 38000, Grenoble, France

${ }^{\mathrm{b}}$ UMR 1253, Imagerie et Cerveau, Université de Tours, Inserm, 37000 Tours, France

${ }^{\mathrm{c}}$ Department of Psychology, Hope College, United States

${ }^{\mathrm{d}}$ Institute for Transport Studies, University of Leeds, LS2 9JT, United Kingdom

e Université catholique de Louvain (UCLouvain), Psychological Sciences Research Institute, Louvain-la-Neuve, Belgium

${ }^{\mathrm{f}}$ Fund for Scientific Research (FNRS-FRS), Brussels, Belgium

g Université Clermont Auvergne, CNRS, LaPSCo, CHU Clermont-Ferrand, WittyFit, F-63000

Clermont-Ferrand, France

\section{Corresponding author:}

Adeline Lacroix, adeline.lacroix@univ-grenoble-alpes.fr

ORCID : https://orcid.org/0000-0001-6990-5949

\section{Other authors can be reached at:}

Marie Gomot,marie.gomot@univ-tours.fr

Gewnhi Park,park@hope.edu

Margot Fombonne, margot.fombonne@gmail.com

Mickaël J. R. Perrier, tsmjrp@leeds.ac.uk

Carole Peyrin, carole.peyrin@univ-grenoble-alpes.fr

Nicolas Vermeulen, nicolas.vermeulen@uclouvain.be

Frédéric Dutheil, fdutheil@chu-clermontferrand.fr

Martial Mermillod, martial.mermillod@univ-grenoble-alpes.fr 


\section{Abstract}

34 High Spatial Frequencies (HSF - conveying local information) may serve a critical role in

35 visual consciousness. Despite an HSF bias during visual perception in autism, autistic

36 individuals demonstrate impairments in face processing. Our aim was to investigate the

37 respective role of HSF and Low Spatial Frequencies (LSF - conveying coarse information) on

38 visual consciousness in autism. Thirty-two autistic adults and 35 typically developing (TD)

39 controls performed an emotional attentional blink paradigm with spatially filtered distractors.

40 TD participants showed reduced T2 accuracy (i.e., accuracy for the second target given the

41 correct report of the first target T1) after unfiltered and HSF distractors compared to LSF

42 distractors. In the autistic group, we observed lower T2 accuracy than controls after HSF and

43 LSF distractors but not after unfiltered distractors. Results suggest the importance of HSF

44 for visual consciousness in TD participants whereas, both LSF and HSF seem important in 45 autism.

46

47

48

49 Keywords: autism; spatial frequencies ; visual consciousness ; attentional blink; face 50 processing 


\section{Introduction}

Efficient face processing play an important role in successful navigation of the social world (see Oruc et al., 2019) and people demonstrate the remarkable ability to process human faces and to identify emotion on faces (Tanaka, 2001). This ability would partly rely on the treatment of low-level information such as orientation and spatial frequencies (Balas and Verdugo, 2018; Oruc et al., 2019). In a visual stimulus, spatial frequency refers to the energy distribution derived from the Fourier transform, and expressed in the number of cycle per degree of visual angle (Park et al., 2012). Coarse information would be conveyed by Low Spatial Frequencies (LSF - below two cycles per degree) mainly by the dorsal stream, while fine information would be conveyed by High Spatial Frequencies (HSF - above six cycles per degree) by the ventral stream (Skottun, 2015). Addressing specifically the question of the interaction between spatial frequency and consciousness during face processing, De Gardelle \& Kouider (2010) demonstrated that HSF information, more than LSF, correlates with consciousness. Previous behavioral studies also showed that HSF components would dominate conscious perception when the exposition time is long enough (Schyns and Oliva, 1994), i.e., more than $100 \mathrm{~ms}$. These findings are corroborated by neurobiological evidence from functional magnetic resonance imaging as the processing of HSF information from faces involved the inferior occipital and fusiform gyri (Iidaka et al., 2004; Vuilleumier et al., 2003), regions implied in conscious perception. Indeed, the recording of single neuron response in the medial temporal lobe showed firing related to conscious perception (Quiroga et al., 2008). Electrophysiological studies also demonstrated that conscious face perception correlates with a boost in the activity of the N170 in the occipito-temporal cortex (Navajas et al., 2013). In sum, there is a body of evidence that HSF would be related to visual consciousness of faces due to the cortical structure underlying their processing.

Autistic individuals are characterized by impairments in several aspects of face processing, included face identification and facial emotion recognition ( Oruc et al., 2018; for reviews see Dawson et al., 2005; Golarai et al., 2006; Tang et al., 2015; Uljarevic and Hamilton, 2013). These impairments may significantly contribute to impaired social interaction, one of the core symptoms of Autism Spectrum Disorders ${ }^{1}$ (ASD). It has been suggested that discrepancy between autistic and typically developing (TD) individuals in face

\footnotetext{
${ }^{1}$ This term is used in keeping with the Diagnostic and Statistical Manual of Mental Disorders, Fifth Edition (DSM-5) but we want to mention and acknowledge that 'autistic person' is usually preferred by people on the spectrum. Both terms are used in the paper.
} 
processing could be partly explained by a different use of LSF and HSF. Autistic persons exhibited a perceptual bias toward local information while processing either non-social (Caplette et al., 2016; Kéïta et al., 2014; Mottron et al., 2006) or social visual stimuli such as emotional faces (Deruelle et al., 2008, 2004; Jemel et al., 2006). Given the HSF bias in autism and the critical role of HSF for visual consciousness of faces, the difficulties encountered by autistic individuals in face processing and emotion recognition are surprising. One explanation could be a reduced sensitivity to HSF in regions associated with consciousness in autism. In line with this hypothesis, Corradi-Dell'Acqua and al. (2014) showed a reduced sensitivity to HSF in a part of the fusiform gyrus (the fusiform face area) in autism compared to control, whereas the response to LSF was intact. Interestingly, this result could also explain that the fusiform face area has often been found hypoactivated in autism during face processing (Golarai et al., 2006). As the fusiform is associated with visual consciousness and belongs to the social brain network, a primary fusiform deficit might disturb several mechanisms relying on face perception, such as emotion recognition (Dawson et al., 2005). However, this result has not been reproduced and moreover, it does not explain the previously reported better use of HSF in autism for categorizing emotional face. Thus, it is unclear which spatial frequencies play a critical role in visual consciousness of emotional faces in autism. Answering this question would help us to understand if there are atypical low-level visual processing that could be linked to atypical visual consciousness of faces in autism and that could explain some difficulties in face processing. We therefore considered that the attentional blink paradigm would be useful for this investigation.

\section{Rapid Serial Visual Presentation paradigms have been utilized to study visual} consciousness by manipulating the time course of attention. During this type of tasks, participants are asked to detect two visual targets (T1 and T2) embedded among a stream of distractors presented at a frequency of about 10 items per second (Shapiro et al., 1997). People typically show high accuracy of detecting the first target T1 (Olivers and Meeter, 2008). However, the conscious perception and the subsequent report of the second target T2 is inconsistent depending on the lag between the two targets (Shapiro et al., 1997). When the lag between T1 and T2 is very short (below $200 \mathrm{~ms}$ ), the detection of the second target T2 is good, often better than the detection of the first target T1, which is called the Lag-1 sparing phenomenon (Olivers and Meeter, 2008). On the contrary, a second target T2 occurring between $200 \mathrm{~ms}$ and $500 \mathrm{~ms}$ after T1 often escape from conscious perception (Olivers and Meeter, 2008), which is called the attentional blink (AB). The boost and bounce theory of 
116 temporal attention (Olivers and Meeter, 2008) explains both the Lag-1 sparing and the AB. As

117 for the Lag-1 sparing, it was assumed that a target stimulus just following T1 would receive

118 an attentional enhancement (boost) from excitatory feedbacks elicited by the visual input

119 whenever relevant information was processed. T1 opened a gate, which then remained opened

120 for subsequent relevant information, which allowed it to enter into working memory.

121 However, irrelevant stimuli would receive strong inhibitory signal that blocked the gate

122 (bounce), inhibiting the conscious perception of T2, thereby resulting in the AB.

Previous research has shown that different types of tasks and individual differences can influence $\mathrm{T} 1$ or $\mathrm{T} 2$ reports. For instance, high similarity between targets and distractors increases the AB (Müsch et al., 2012), while emotional stimuli decreases it (De Jong et al., 2009; Maratos et al., 2008). Also, T1 and T2 report could vary according to the category they belong (e.g., animals are more reliably detected than plants - Balas and Momsen, 2014) and could be modulated by individual differences such as age (Georgiou-Karistianis et al., 2007), Full Scale Intelligence Quotient (Colzato et al., 2007) or by a diagnosis such as schizophrenia

130 (Mathis et al., 2011), attention deficit disorder (Amador-Campos et al., 2015) or also autism.

131 There was no difference in the AB magnitude between TD and autistic participants when

132 letter stimuli were used (Amirault et al., 2009; Rinehart et al., 2010). However, when T2 were 133 emotional words, compared to neutral words or male names, an enhancement of T2 report 134 was observed in TD controls, i.e., reduced $\mathrm{AB}$, which was attenuated in autistic individuals, 135 i.e., less reduced $\mathrm{AB}$ compared to control (Gaigg and Bowler, 2009). Nonetheless, when the 136 effect of emotional faces was explored by using angry and neutral faces as targets, no 137 difference were found between autistic children and the control group: ASD and TD showed 138 better T2 accuracy for angry targets compared to neutral targets, and the magnitude of the 139 effect was similar for both groups (Yerys et al., 2013). Yerys and al. (2013) made several 140 hypotheses to explain different results in their experiment from those of Gaigg and Bowler 141 (2009). First, the arousal levels of the stimuli might differ between the two experiments.

142 Second, Gaigg and Bowler experiment required verbal abilities as stimuli are words, while 143 Yerys and al. pictorial AB task required lower-level abilities. Finaly, they hypothesized that 144 low similarity between targets (dog for T1 and emotional or neutral face for T2) and 145 distractors (non-meaningful scrambled faces) in their experiment enhanced salience of targets 146 among distractors. In other words, they supposed that low similarity between targets and 147 distractors facilitated target detection by intensifying the emotional valence of faces, thereby 148 enhancing performances in autistic participants and reducing differences between the groups 
149 on emotional stimuli. On the contrary, high similarity between targets and distractors can account for an increased AB as shown in TD (Müsch et al., 2012; Visser et al., 2004).

The aim of our current study was to investigate the link between visual consciousness of emotional face stimuli, operationally defined by the $\mathrm{AB}$, and fundamental low-level visual 153 processing, operationally defined by using spatial frequencies, in autism compared to TD participants. We created an $\mathrm{AB}$ task, where participants had to detect two unfiltered happy faces (T1 and T2) in a stream of angry faces distractors, which were either in LSF, HSF or unfiltered. We chose happy and angry emotions because it is easy to differentiate them. Happiness is not confused with other emotions and the salient and distinctive smile of happy faces is easily identified, probably because the recognition of facial expression relies more on perceptual processing than on affective dimensions (Calvo and Nummenmaa, 2016). Happy faces are usually well recognized by autistic participants (similarly as control; for a metaanalysis, see Uljarevic \& Hamilton, 2013), but this might be the result of efficient compensatory strategies based on cognitive and linguistic resources (Harms et al., 2010). Hence, using happy faces enabled us to focus on the role that HSF and LSF played in visual consciousness of emotional faces in autism, while keeping the task feasible by autistic participants. We capitalized on the finding that spatial-frequency filtered distractors would allow us to manipulate similarity between targets and distractors: the more similar the target and the distractors would be, the greater the $\mathrm{AB}$. We reasoned that, manipulating spatial frequency filtering of the distractors, more than targets, was an interesting way to investigate incidentally which type of low-level information is important for visual consciousness, while keeping a target ecologically intact. In this experiment, we tested three main hypotheses. Firstly, we predicted a strong AB effect in both groups, as distractors have a high degree of similarity with targets because they are all faces. Secondly, given a pivotal role that HSF plays in visual consciousness during face processing, we expected a stronger AB after HSF and unfiltered distractors (as it also contains HSF) compared to LSF distractors in both groups. Lastly, due to the HSF bias for emotional face recognition in ASD, autistic participants would be significantly more disturbed by HSF distractors than TD participants.

Similar to other AB studies, we controlled for T1 accuracy. We also assessed the Full

178 Scale Intelligence Quotient (FSIQ), verbal Intelligence Quotient (VIQ), Performance

179 Intelligence Quotient (PIQ), Autism spectrum Quotient (AQ - Baron-Cohen et al., 2001) and 180 age, to control for these variables (Gaigg and Bowler, 2009; Georgiou-Karistianis et al., 2007). 


\section{Participants}

Sample size was determined according to studies comparing autistic and control groups during an AB task (Gaigg and Bowler, 2009; Yerys et al., 2013), as there was no study investigating spatial frequencies in a $\mathrm{AB}$ task allowing a proper power analysis. Thirty-three autistic adults (15 females, 15 males, 2 transgenders female-to-male) and 35 TD control adults (17 females, 17 males, and 1 transgender female-to-male) were recruited for this study. We recruited a similar number of males and females on purpose, as a second task was performed by the participants after the $\mathrm{AB}$ task, in which sex differences were investigated. One autistic man was excluded from the analysis as the task was too difficult for him and he skipped all answers. All participants were aged from 19 to 47 years and had a FSIQ > 70, as estimated using a Wechsler Intelligence Scale (Wechsler Intelligence Scale for Children, 4th Edition WISC-IV; Wechsler, 2003 - or Wechsler Adult Intelligence Scale, 3rd or 4th Edition -WAISIII ; Wechsler, 1997 - or WAIS-IV; Wechsler, 2008). They all reported a normal or correctedto-normal vision.

Autistic participants were recruited through local community, with the help of local

198 Expertise Centers dedicated to autism diagnosis, clinicians specialized in ASD support or associations for the autistic community. We ensured that they previously received a clinical diagnosis based on the DSM-IV-R (American Psychiatric Association, 2003) or DSM-5

201 (American Psychiatric Association, 2013) criteria or on the International Classification of

202 Disease $10^{\text {th }}$ revision (OMS and Collectif, 1992) by asking them to show us the written report of their diagnosis. We collected the scores of the Autism Diagnostic Observation Schedule

204 (Lord et al., 1989), the Autism Diagnostic Interview-Revised (Lord et al., 1994) and IQ when 205 they were available. Their age at diagnosis was between 10 and 45 years old (mean $=28.5$, $206 \mathrm{SD}=10.1)$. Three of them also received a diagnosis of attention deficit with or without hyperactivity disorder (one of them was treated with methylphenidate); two received a diagnosis of anxiety disorder and two had a history of traumatic brain injury. Two were receiving neuroleptic medication and six were used to take antidepressant when they were enrolled in the study but were stabilized with the treatment. Twenty-one autistic participants

211 had neither other diagnosis nor treatment. For those who could not provide available IQ data

212 (8 individuals), an estimation of their FSIQ, VIQ, and PIQ was performed using four selected 213 subtests (Vocabulary, Similarities, Block Design and Matrix) of the WAIS-IV (Grégoire and

214 Wierzbicki, 2009; Wechsler, 2008). Note that 10 ASD participants scored below the cut-off of 
21532 on the AQ. We kept them as AQ does not fully capture autism symptoms in autistic

216 persons who have poor insight (Bishop and Seltzer, 2012), showed by a weak correlation with

217 ADOS scores sometimes (Ashwood et al., 2016). Indeed, AQ scores were primary collected

218 to remove TD participants with high AQ but was not aimed to exclude ASD participants as

219 they have been diagnosed by expert professionals. Detailed information and scores for each

220 participant can be found in the following repository :

221 https://osf.io/maqvz/?view_only=3002780bdf8247ecb3669e9870b4c00d.

TD adults were recruited via advertisements and mailing list. They didn't have any neurological, neurodevelopmental or psychiatric diagnosis. As far as possible, groups were

224 paired on sex, age and education. An estimation of their FSIQ, VIQ, and PIQ was performed.

After having checked assumptions, we performed two-sample t-test. Groups did not differ on age, education, VIQ, and FSIQ. Nevertheless, it is worth noting that differences between groups on FSIQ is approaching the significance threshold and may be related to the significant difference between groups on PIQ. As predicted, groups differed on the AQ. All relevant statistics regarding groups description are set out in Table 1.

Table 1: Subject demographics - Means (M), standard deviations (SD) and ranges. FSIQ = Full Scale Intelligence Quotient; VIQ = Verbal Intelligence Quotient; PIQ = Performance Intelligence Quotient ; AQ =

232 Autism-Spectrum Quotient.

\begin{tabular}{lllllllll}
\hline & \multicolumn{2}{l}{ TD $(\mathrm{n}=35)$} & \multicolumn{2}{l}{ ASD $(\mathrm{n}=32)$} & T-test & Effect size \\
\hline & $M$ & $S D$ & Range & $M$ & $S D$ & Range & $p$ & Cohen's $d$ \\
Age & 31.9 & 7.6 & $19-44$ & 32.7 & 8.3 & $19-47$ & .702 & \\
Education & 15.9 & 2.7 & $10-24$ & 14.6 & 2.7 & $9-20$ & .052 & \\
FSIQ & 114.5 & 14.6 & $74-160$ & 122.5 & 18.2 & $70-155$ & .051 & \\
VIQ & 121.7 & 15.8 & $88-150$ & 127.6 & 17.5 & $72-150$ & .242 & .66 (medium) \\
PIQ & 103.8 & 14.4 & $68-150$ & 113.7 & 15.7 & $70-142$ & $<.01$ & 2.79 (large) \\
AQ & 15.3 & 6.1 & $4-29$ & 35.3 & 8.1 & $18-47$ & $<.001^{* * * *}$ & 2.72 \\
Age at diagnosis & & & & 28.8 & 10.5 & $10-45$ & & \\
\hline
\end{tabular}

233

234

235

After a verbal instruction, written informed consent was obtained from all individual participants. Participants received a monetary compensation for their participation at the end of the study.

All procedures performed in this study involving human participants were in accordance with the Code of Ethics of the World Medical Association (Declaration of 
Helsinki) and approved by the local ethics committee (CER-Grenoble Alps, COMUE University Grenoble Alpes, IRB00010290).

\section{Material}

The stimulus set comprised 80 faces on a grey background from the Chicago Faces Database (Ma et al., 2015): 20 females and 20 males, Caucasians, aged between 18 and 40, expressing either happiness with open mouth for targets or anger with closed mouth for distractors. We carefully controlled the gender of stimuli since it may cause gender bias interacting with emotions (Plant et al., 2004; Villepoux et al., 2015). They were high resolution $(2444 \times 1718$ pixels $)$ and cropped to a $2288 \times 1716$ pixel size $\left(18.4^{\circ} \times 13.8^{\circ}\right)$. All stimuli were converted to 256 gray levels by averaging the red, green, and blue values of each pixel, then exported into a BMP format in order to standardize file size and load speed. Happy faces were the target stimuli and always presented unfiltered (i.e., in Broad Spatial Frequency - BSF). Angry faces were distractors and were presented either in BSF, LSF containing only frequencies below two cycles per degree of visual angle (corresponding to 36.89 cycles per image width, that is 10.78 cycles per face), or HSF containing only frequencies above six cycles per degree of visual angle (corresponding 110.69 cycles per image width, that is, 31.44 cycles per face). We used a pseudo-randomized list of stimuli. This list was constructed so that for each trial all individuals in our sample of the Chicago Face Database were randomly ordered, then assigned an emotional facial expression and an image filtering according to their timing in the RSVP. Four individuals that did not appear in the RSVP were used for the multiple choices at the end of the trial. Individuals' gender was therefore entirely random and the order of appearance of the 180 trials was randomized by E-Prime (Psychology Software Tools Inc., Pittsburg, PA). Examples of stimuli and distractors can be seen on Figure 1. Stimuli were equalized in luminance and contrast (Kauffmann et al., 2015). Filtering and equalizing procedures were performed using MATLAB (Mathworks Inc., Sherborn, MA, USA). Stimuli were displayed in a darkened experimental box of the Psychology and NeuroCognition Laboratory (Grenoble Alpes University), on a 23-inch LCD monitor Dell $\mathrm{P} 2319 \mathrm{H}$ (refresh rate $=75 \mathrm{~Hz}$ ) at a viewing distance of $117 \mathrm{~cm}$. To maintain the distance and central position, participants' head was supported by a chinrest. E-prime version 2.0 (Psychology Software Tools Inc., Pittsburg, PA) was used to exhibit stimuli and collect behavioral data. As some participants could not easily come many times to the laboratory, on the same day, after the $\mathrm{AB}$ task of 30 minutes duration, they also did another 15 minutes study, after a break. If needed, IQ estimation was done after these tasks. 
A.
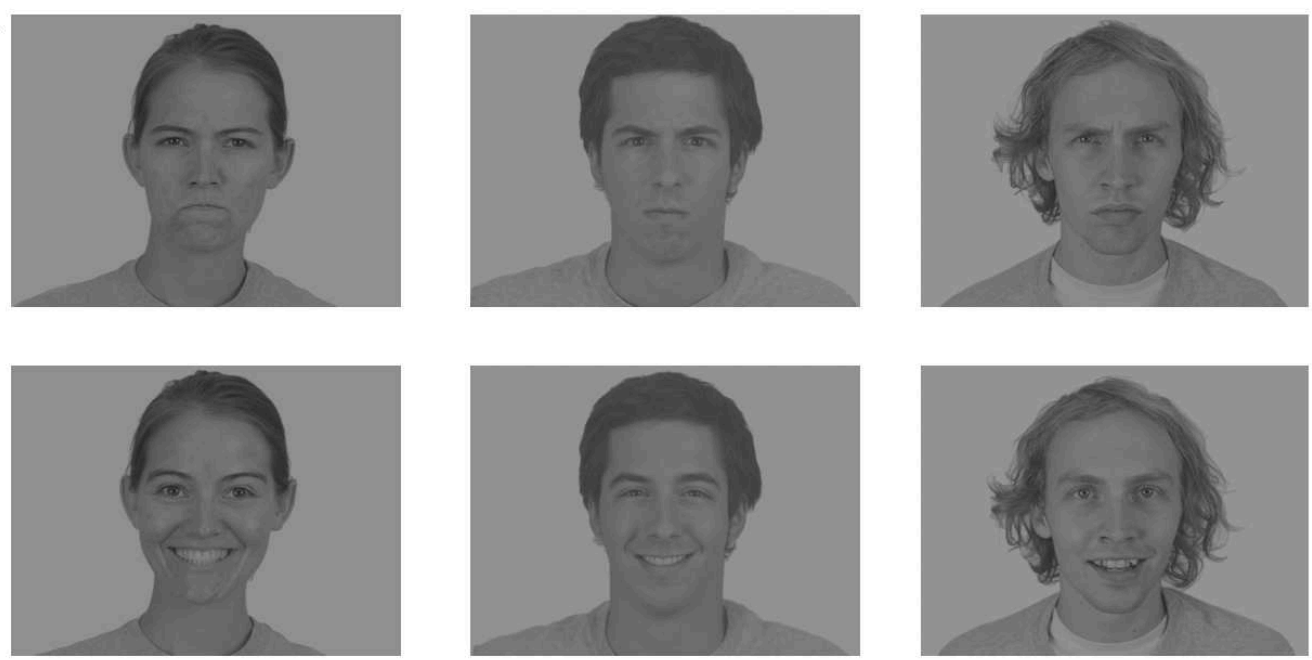

B.
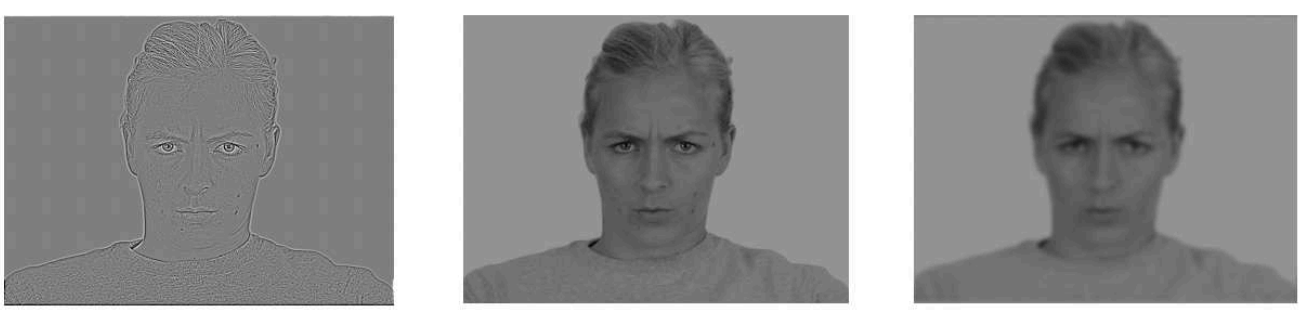

Figure 1. A. Examples of happy and angry stimuli used during the task. B. Examples of distractors used during the task. The left one is in High Spatial Frequencies (HSF), the middle one is unfiltered (BSF) and the right one is in Low Spatial Frequencies (LSF).

\section{Procedure}

Instructions were given both orally and on a written form. Each participant performed

276 the task individually. Participants were informed that a stream of angry faces would be

277 displayed, two happy faces would appear among them and should be memorized in order to

278 recognize each of them among three others at the end of the stream. They were informed of

279 the rapid presentation and were instructed to concentrate a lot for the task. A training session

280 of 8 trials was performed by the participant before the experimental session of 180 trials,

281 which included three breaks (every 45 trials) in order to decrease the attentional load required

282 by the task and allow participants to rest their eyes. During the training session, the

283 experimenter stayed with the participant in order to ensure that instructions had been correctly

284 understood and to reassure the participant if the task's difficulty generated anxiety. After this

285 training session, the experimenter left the room. Each trial began with a fixation cross for

286 approximately 1,000 milliseconds (ms), followed by a sequence of four, five, six or seven 
287 unfiltered angry faces followed by T1 (an unfiltered happy face). The second unfiltered happy 288 face T2 appeared after a second serial of two (Lag 3), four (Lag 5) or six (Lag 7) distractors,

289 which were either in BSF, LSF, or HSF. Lag 0 corresponds to the onset of T1. Each stimulus

290 had a duration of $133 \mathrm{~ms}$. Accordingly, stimulus onset asynchrony was either $399 \mathrm{~ms}$ (Lag 3),

$291665 \mathrm{~ms}$ (Lag 5), or $931 \mathrm{~ms}$ (Lag 7). As emotional faces are complex stimuli, longer

292 presentation times have been required compared to experiments using letters, in order to

293 reduce task difficulty. For each trial, distractors were similarly filtered and five unfiltered

294 distractors remained after T2. After this rapid serial visual presentation, a screen appeared for

$2954,000 \mathrm{~ms}$ with three happy faces on the upper half. Right-handed participants had to choose

296 which of these three faces corresponded to T1 by pressing one of the three corresponding

297 buttons on the right side of the Chronos ${ }^{\circledR}$ device (Psychology Software Tools). Importantly,

298 participants were instructed not to answer randomly and had to press the far-left button if they

299 had no idea about the answer. For left-handed participants, the buttons were situated on the

300 left side to facilitate the motor response. Then, a second screen appeared for the same duration

301 with three unfiltered happy faces displayed on the lower half; this was made to ensure

302 participants would notice the change. Participants were instructed to find T2 among the three

303 faces. The schematic of one trial is shown in Figure 2. 


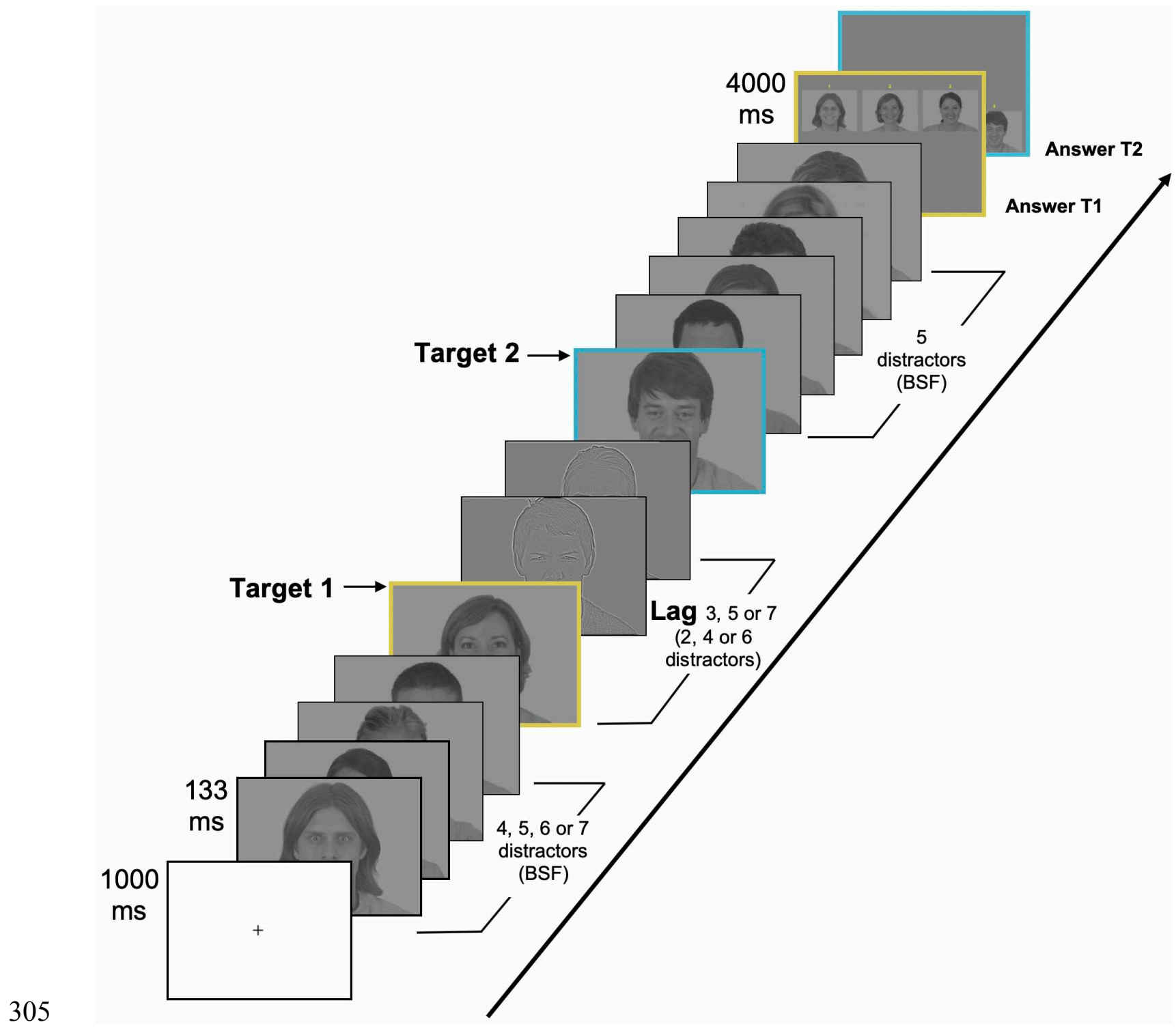

Figure 2 Example of a trial with HSF as distractors. Target 1 has to be selected among other faces on the Answer 1 slide and Target 2 has to be selected among other faces on the Answer 2 slide.

\section{Results}

311 All figures and analyses were done using $\mathrm{R}$ version 3.6.1 and R Studio version 1.2.5019 (R

312 Core Team, 2019). 


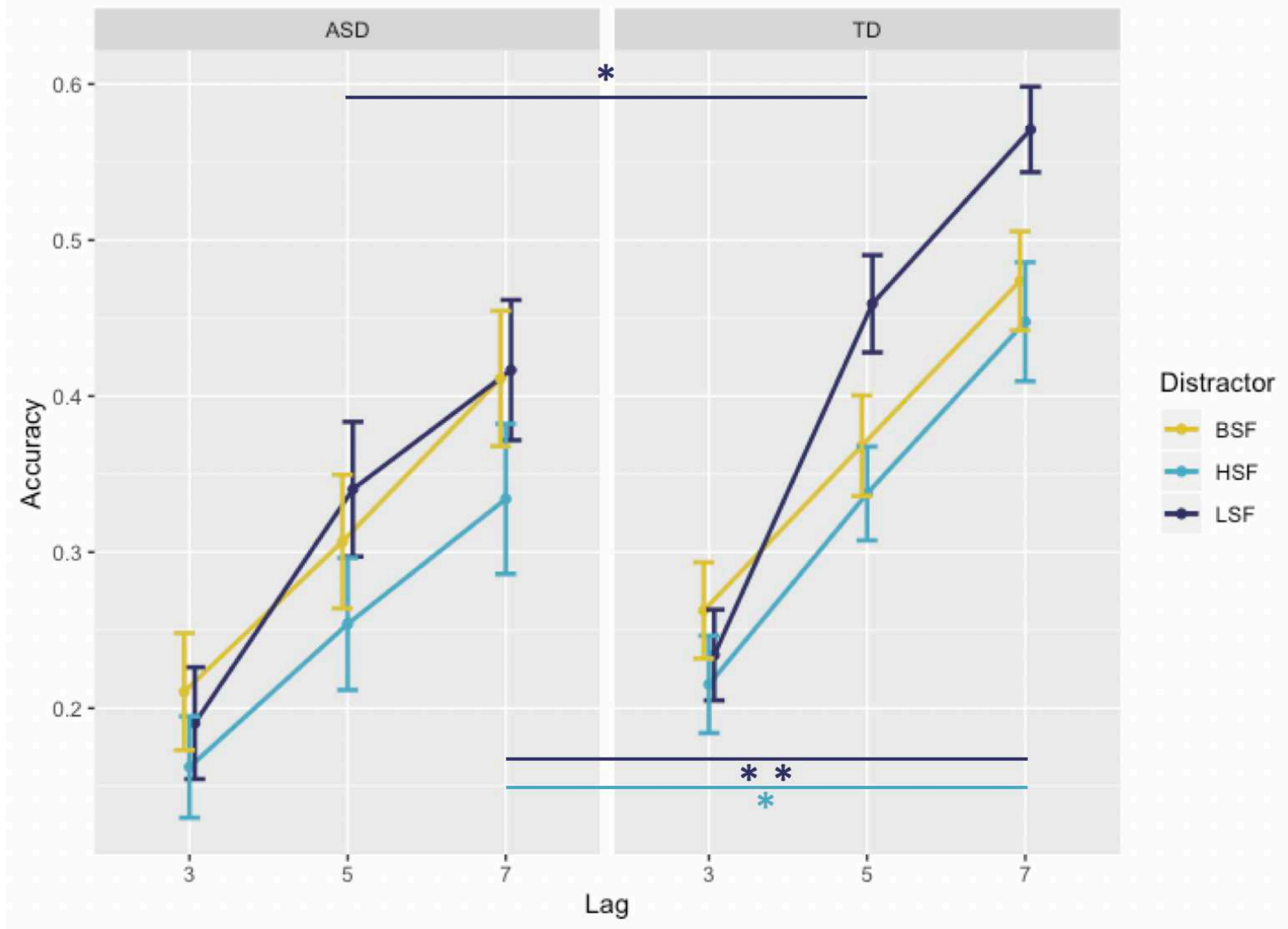

Figure 3. Mean T2 accuracy (given a correct answer on T1) and standard errors by group for each Lag and in 317 each Distractor condition. Only significant between groups differences for each Distractor type depending on 318 Lag are represented $(*=\mathrm{p}<.05, * *=\mathrm{p}<.005)$.

\begin{tabular}{|c|c|c|c|c|c|c|c|c|c|c|}
\hline & TD & & & ASD & & & All & & & \\
\hline Distractor & Lag 3 & Lag 5 & Lag7 & Lag 3 & Lag 5 & Lag7 & Lag 3 & Lag 5 & Lag7 & $\begin{array}{l}\text { Mean for } \\
\text { each } \\
\text { Distractor }\end{array}$ \\
\hline BSF & $\begin{array}{l}26.3 \% \\
(3.1)\end{array}$ & $\begin{array}{l}36.8 \% \\
(3.2)\end{array}$ & $\begin{array}{l}47.4 \% \\
(3.2)\end{array}$ & $\begin{array}{l}21.1 \% \\
(3.8)\end{array}$ & $\begin{array}{l}30.7 \% \\
(4.3)\end{array}$ & $\begin{array}{l}41.1 \% \\
(4.3)\end{array}$ & $\begin{array}{l}23.8 \% \\
(2.4)\end{array}$ & $\begin{array}{l}33.9 \% \\
(2.7)\end{array}$ & $\begin{array}{l}44.4 \% \\
(2.7)\end{array}$ & $\begin{array}{l}34.0 \% \\
(1.6)\end{array}$ \\
\hline LSF & $\begin{array}{l}23.4 \% \\
(2.9)\end{array}$ & $\begin{array}{l}45.9 \% \\
(3.1)\end{array}$ & $\begin{array}{l}57.1 \% \\
(2.7)\end{array}$ & $\begin{array}{l}19.0 \% \\
(3.6)\end{array}$ & $\begin{array}{l}34.0 \% \\
(4.3)\end{array}$ & $\begin{array}{l}41.7 \% \\
(4.5)\end{array}$ & $\begin{array}{l}21.3 \% \\
(2.3)\end{array}$ & $\begin{array}{l}40.2 \% \\
(2.7)\end{array}$ & $\begin{array}{l}49.7 \% \\
(2.7)\end{array}$ & $\begin{array}{l}37.1 \% \\
(1.7)\end{array}$ \\
\hline HSF & $\begin{array}{l}21.5 \% \\
(3.1)\end{array}$ & $\begin{array}{l}33.8 \% \\
(3.0)\end{array}$ & $\begin{array}{l}44.8 \% \\
(3.8)\end{array}$ & $\begin{array}{l}16.2 \% \\
(3.3)\end{array}$ & $\begin{array}{l}25.4 \% \\
(4.2)\end{array}$ & $\begin{array}{l}33.4 \% \\
(4.8)\end{array}$ & $\begin{array}{l}19.0 \% \\
(2.3)\end{array}$ & $\begin{array}{l}29.8 \% \\
(2.6)\end{array}$ & $\begin{array}{l}39.3 \% \\
(3.1)\end{array}$ & $\begin{array}{l}29.4 \% \\
(1.6)\end{array}$ \\
\hline $\begin{array}{l}\text { Mean for } \\
\text { each Lag }\end{array}$ & $\begin{array}{l}23.7 \% \\
(1.7)\end{array}$ & $\begin{array}{l}38.8 \% \\
(1.9)\end{array}$ & $\begin{array}{l}49.7 \% \\
(1.9)\end{array}$ & $\begin{array}{l}18.8 \% \\
(2.0)\end{array}$ & $\begin{array}{l}24.2 \% \\
(2.5)\end{array}$ & $\begin{array}{l}38.7 \% \\
(2.6)\end{array}$ & $\begin{array}{l}21.4 \% \\
(1.3)\end{array}$ & $\begin{array}{l}34.6 \% \\
(1.6)\end{array}$ & $\begin{array}{l}44.5 \% \\
(1.7)\end{array}$ & \\
\hline $\begin{array}{l}\text { General } \\
\text { mean }\end{array}$ & \multicolumn{3}{|c|}{$37.4 \%(1.2)$} & \multicolumn{3}{|c|}{$29.2 \%(1.5)$} & \multicolumn{3}{|c|}{$33.5 \%(0.9)$} & \\
\hline
\end{tabular}


We calculated the correct response rate (accuracy) for T2 given that T1 was correctly reported (Gaigg and Bowler, 2009; Shapiro et al., 1997; Yerys et al., 2013) for each of the experimental conditions. This latter is abbreviated "T2 accuracy" in the following text. Figure 3 represents the T2 accuracy for each group (ASD, TD) as a function of $\operatorname{Lag}(3,5$, and 7$)$ and Distractor (BSF, HSF, and LSF). All means and standard errors for T2 accuracy are reported in Table 2. We conducted a mixed-design ANOVA with Group (ASD vs TD participants) as a between subject factor, and Lag (3, 5 or 7) and Distractor (BSF, LSF or HSF) as withinsubject factors. Assumptions of sphericity were tested with Mauchly Test. As there was no violation of sphericity, no correction was required. The normality assumption on residuals were visually inspected with histogram and qq-plot, and tested with a Shapiro-Wilk test.

The analysis revealed three significant main effects. The main effect of Group $\left(F(1,65)=4.14, p=.04, \eta^{2}=.04\right)$, indicated that overall $\mathrm{T} 2$ accuracy of ASD participants was significantly lower than overall T2 accuracy of TD participants. A main effect of Lag $\left(F(1,85)=104.8, p<.001, \eta^{2}=.17\right)$ was also found. Post-hoc paired t-test with Tukey adjustment showed that T2 accuracy at Lag 3 was worse than T2 accuracy at Lag 5 $(t(130)=-8.27, p<.001, d=-0.65)$, which was also worse than T2 accuracy at Lag 7 $(t(130)=-6.15, p<.001, d=-0.43)$. These findings demonstrate the expected AB in our paradigm (both groups taken together). Finally, we observed a main effect of Distractor $\left(F(1,88)=17.68, p<.001, \eta^{2}=.02\right)$. Post-hoc paired t-test with Tukey adjustment revealed that T2 accuracy after HSF distractors was lower than after BSF distractors $(t(130)=3.61$, $p=.001, d=-0.21)$, and lower than after LSF distractors $(t(130)=-5.90, p<.001$, $d=-0.32$ ). These findings revealed that HSF produced a greater AB than other distractors when groups were taken together. However, the difference between T2 accuracy after BSF distractors and after LSF distractors was not significant.

There was also a significant Lag $\times$ Distractor interaction $\left(F(3,85)=2.96, p=.02, \eta^{2}=.007\right)$, attesting that the effects of distractors were different depending on the Lag. Paired t-test with Tukey adjustment revealed that T2 accuracy was lower for HSF than LSF at Lag 5 $(t(390)=-4.66, p<.001, d=-0.48)$ and at $\operatorname{Lag} 7(t(390)=-4.61, p<.001, d=-0.43)$. This was not observed at Lag 3, suggesting that the greater AB followed by HSF compared to LSF appeared only at longer lags ( 5 and 7). Moreover, T2 accuracy was significantly lower for BSF than LSF at Lag $5(t(390)=-2.79, p<.02, d=-0.29)$, but not at Lag 3, and only marginally significant at $\operatorname{Lag} 7(t(390)=-2.29, p=.058, d=-0.24)$. Hence, BSF distractors also produced a greater AB than LSF distractors at longer lags. 
356 The data set out in Figure 3 suggests that the lack of significant difference between BSF and

357 LSF at Lag 7, which was not expected, could be explained by a different pattern in each

358 group. This led us to perform within-group paired t-test with Tukey adjustment although the

359 foregoing analysis provided no interaction involving the group factor (Group $\times$ Distractor: $F$

$360(1,88)=1.62, p=.20$; Group $\times \operatorname{Lag} \times$ Distractor: $F(3,85)=0.67, p=.60)$. In the TD group,

361 a significant difference in T2 accuracy exists between HSF and LSF at Lag 5

$362(t(390)=-3.94, p<.001, d=-0.67)$ and at $\operatorname{Lag} 7(t(390)=-3.99, p<.001, d=-0.62)$,

363 and between BSF and LSF at Lag $5(t(390)=-2.95, p=.009, d=-0.48)$ and at Lag 7

$364(t(390)=-3.14, p=.005, d=-0.55)$. These findings indicate that, as expected, HSF and

365 BSF distractors produce a greater AB than LSF distractors at longer lags (5 and 7) in TD

366 participants. In the ASD group there is a difference in T2 accuracy between HSF and LSF at

$367 \operatorname{lag} 5(t(390)=-2.68, p=.02, d=-0.36)$ and at $\operatorname{Lag} 7(t(390)=-2.56, p=.02$,

$368 d=-0.31)$. However, there is no significant difference between BSF and LSF, neither at Lag

3695 , nor at Lag 7. Hence, in the ASD group, only HSF distractors produced a greater AB than

370 LSF distractors at longer lags ( 5 and 7). These differences between groups could therefore

371 explain the lack of significance previously found at Lag 7 between BSF and LSF in the main

372 effect and in the interaction. Moreover, the analysis showed a difference in T2 accuracy

373 between BSF and HSF at Lag $7(t(390)=2.39, p=.04, d=0.30)$ for the ASD group,

374 suggesting greater AB after HSF distractors compared to BSF distractors at the longest lag.

375 Finally, we tested our main hypothesis: HSF distractors would produce a greater AB than LSF

376 distractors for the ASD group as compared to the control group. We performed between-

377 group paired t-tests with Tukey adjustment for each distractor type and within each Lag. The

378 expected between-group difference on T2 accuracy after HSF distractors was only found at

$379 \operatorname{Lag} 7(t(161)=-2.21, p=.03, d=-0.46)$. Differences between groups on T2 accuracy

380 were also found after LSF distractors at $\operatorname{Lag} 5(t(161)=-2.31, p=.02, d=-0.55)$ and at

$381 \operatorname{Lag} 7(t(161)=-3.00, p=.003, d=-0.73)$. These unexpected findings indicate that LSF

382 distractors also produce a greater AB for the ASD group as compared to the TD group at 383 longer lags (5 and 7). No between-group differences in T2 accuracy were found after BSF

384 distractors. These results are represented on Figure 3. 
Analysis on T1

388 We calculated a correct response rate for $\mathrm{T} 1$ for each participant. The latter is abbreviated by 389 "T1 accuracy" in the text. As variances were unequal, we performed a Mann-Whitney-

390 Wilcoxon test. The test was not significant, indicating that T1 accuracy of autistic participants $391(M=52.7, S E=1.4)$ does not significantly differ from T1 accuracy of TD participants $392(M=58.0, S E=0.8)$.

\section{Correlation analysis}

395 Correlations plots between AQ, Age, as well as the estimations of FSIQ, VIQ, and PIQ with 396 the T2 accuracy and the T1 accuracy are represented on Figure $4 \mathrm{~A}$ and Figure $4 \mathrm{~B}$

397 respectively. We did not find any significant correlation between T2 accuracy and AQ, FSIQ, 398 nor VIQ. A significant negative correlation between age and T2 accuracy was found for the 399 TD group only $(r=-.43, p<.01)$, indicating that the older the TD participants, the stronger 400 the $\mathrm{AB}$. We also found a significant negative correlation between age and $\mathrm{T} 1$ accuracy in the 401 TD group $(r=-.35, p<.05)$, revealing that the older TD participants are, the lower is their 402 T1 accuracy. Finally, we found a significant positive correlation between T1 accuracy and 403 FSIQ in the TD group $(r=.41, p<.05)$ and in the ASD group $(r=.39, p<.05)$, indicating 404 that the higher FSIQ is, the better is the T1 accuracy. We also found significant positive 405 correlations between T1 accuracy and PIQ in the TD group $(r=.46, p<.01)$ and in the ASD 406 group $(r=.40, p<.05)$, revealing that the higher the PIQ is, the better is the T1 accuracy. 
A.
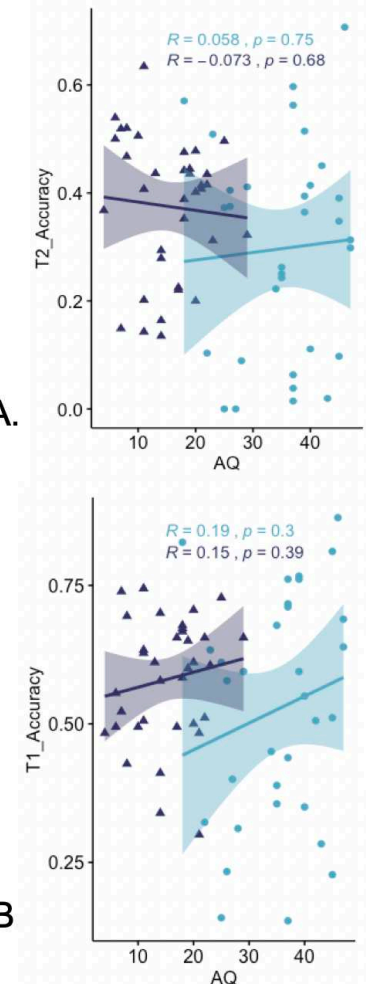
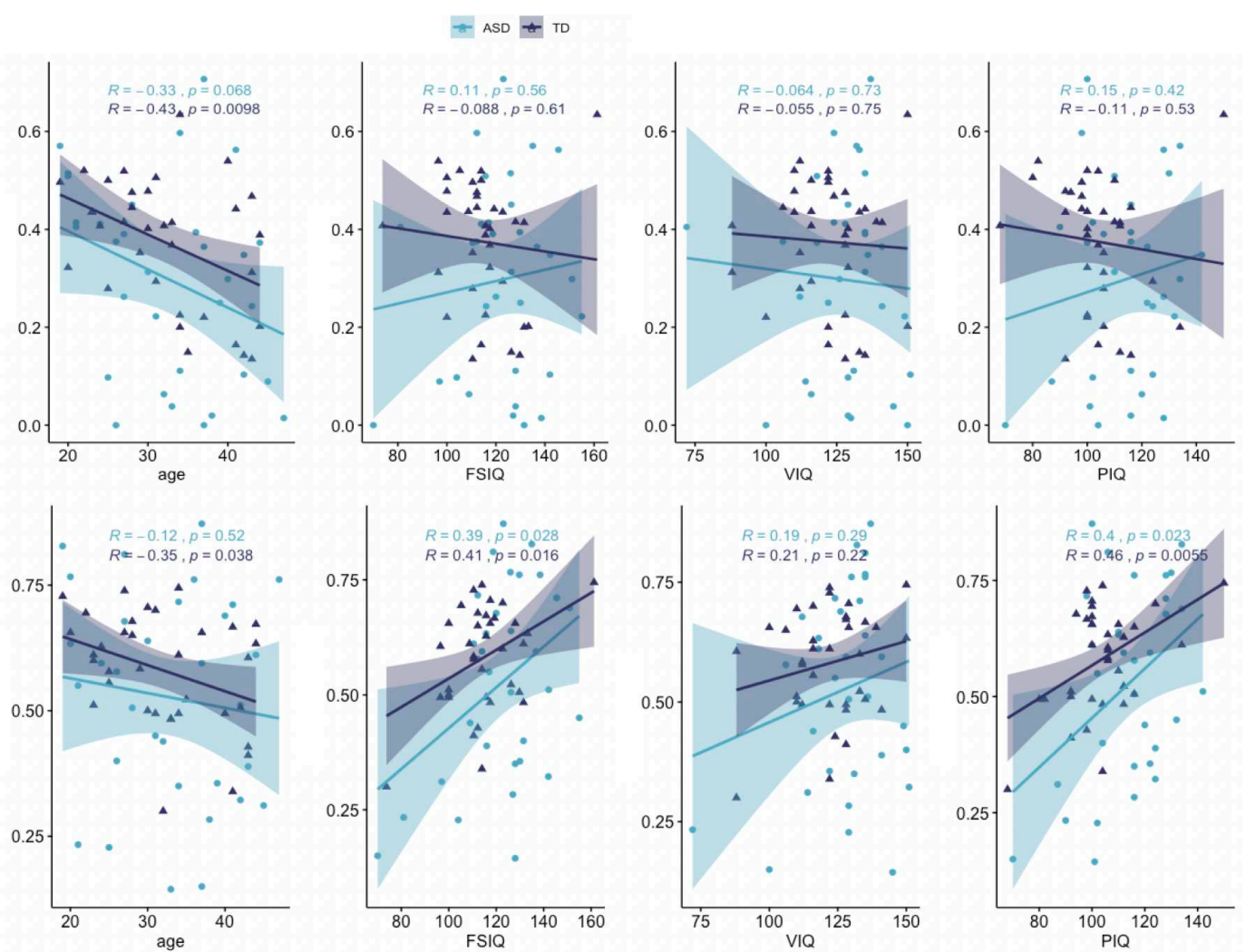

Figure 4. A. Correlation plots between T2 accuracy (given correct answer on T1) and Autism-Spectrum Quotient

409 (AQ), age, as well as estimations of Full-Scale Intelligence Quotient (FSIQ), Verbal Intelligence Quotient (VIQ),

410 and Performance Intelligence Quotient (PIQ). B. Correlation plots between T1 accuracy and AQ, age, as well as

411 estimations of FSIQ, VIQ and PIQ.

412

\section{Discussion}

414 The current study used an AB paradigm with spatial-frequency filtered distractors to 415 investigate which spatial frequencies play a critical role in visual consciousness in autistic 416 adults compared to TD control participants.

Replicating previous results on AB in TD people (Olivers and Meeter, 2008; Shapiro et 418 al., 1997) and in ASD (Amirault et al., 2009; Gaigg and Bowler, 2009; Rinehart et al., 2010;

419 Yerys et al., 2013), our results elicited a strong AB, as T2 accuracy was reduced for shorter 420 lags and increased with longer lags. This finding is consistent with our first hypothesis.

421 Although the timings of Lag $5(665 \mathrm{~ms})$ and $7(931 \mathrm{~ms})$ would usually be considered outside 422 of the $A B$ timeframe, we suggest that the $A B$ is observed in longer lags here due to the task 423 difficulty. Indeed, the AB magnitude can be modulated by factors such as task demands 424 (Elliott and Giesbrecht, 2010; Shore et al., 2001). 
consistent with our second hypothesis. This result provides new evidence that HSF could play a primary role in visual consciousness, particularly of emotional faces, as previously suggested (De Gardelle and Kouider, 2010; Schyns and Oliva, 1994). As HSF are mainly conveyed by the ventral stream, our findings could support the idea that visual consciousness emerged, at least in part, from the temporal pathway processing (Navajas et al., 2013; Quiroga et al., 2008; Sergent et al., 2005). It should be noted that the difference between BSF and LSF at Lag 7 was only marginally significant. This could be explained by differences between groups on LSF distractors, which will be further discussed. No difference between distractors at Lag 3 can be explained by the strength of the $\mathrm{AB}$ at that lag.

Based on previous findings of perceptual bias favoring HSF information in autism, in general and particularly for emotional face recognition (Caplette et al., 2016; Deruelle et al., 2008, 2004; Jemel et al., 2006; Mottron et al., 2006), we predicted that autistic participants would show significantly reduced T2 accuracy in response to the HSF content of inter-target distractors compared to TD control participants. While there was no difference between groups on T2 accuracy according to distractor types at Lag 3, probably due to the strong AB effect at Lag 3 for both groups, group differences emerged at Lags 5 and 7. Of particular importance is lower T2 accuracy for autistic participants, compared to TD, after HSF distractors at Lag 7, which partially support our hypothesis. Interestingly, at Lags 5 and 7, our analysis also revealed that, in the ASD group, T2 accuracy after BSF were not lower than T2 accuracy after LSF, contrary to the control group and T2 accuracy for the ASD group after LSF distractors was unexpectedly lower as compared to the TD group. Additionally, we did not observe differences between groups on BSF. The latter finding indicates that the main effect of group observed on T2 accuracy in our experiment could be more related to the filtered nature of the distractors than to the emotional content, which could have reduced the $\mathrm{AB}$ in TD participants compared to ASD as it has been observed by Gaigg \& Bowler (2009). Taken together, these results suggest that low level visual characteristics of both HSF and LSF could be critical for visual consciousness of emotional faces in autism, which may be different from how TD engage in visual processing. In other words, contrary to TD, autistic individuals might require a full spectrum of low-level visual information (i.e., more information than TD) for visual consciousness of emotional faces. Our results could be in line with the Enhanced Perceptual Functioning theory (Mottron et al., 2006) as they revealed a heightened sensitivity to low level characteristics. At a neural level, heightened low-level visual perception in autism could be related to superior functioning of the most posterior 
460 region of the visual brain (Mottron et al., 2006). Our findings are also in line with the

461 different pattern of activation between autistic individuals and control during the processing

462 of emotional faces, the former exhibiting an increased sensitivity to LSF in the ventral

463 occipital cortex (Corradi-Dell'Acqua et al., 2014). This atypical spatial frequencies processing

464 at later stages of visual perception, particularly in temporal areas which are more involved in

465 conscious perception (Sergent et al., 2005), might impair visual consciousness of emotional

466 faces. In sum, atypical processing of low-level information in autism may result in enhanced

467 low-level information sensitivity but in less efficient visuo-integrative processes, leading to

468 atypical visual consciousness which may partly explain the difficulties for autistic individuals

469 in face perception and emotion recognition. However, some alternative hypotheses could also

470 explain the results. Indeed, impairments could also come from other cognitive and affective

471 processes such as hose describe hereafter.

472 Particularly, alexithymia, which can be describe as the inability to identify and 473 describe its own emotions, is associated with autism in around $50 \%$ of the individuals (for a

474 review and meta-analysis see Kinnaird et al., 2019). In addition to self-reported measure, 475 alexithymia in autism (and in TD) is also associated with psychological markers such as 476 reduced skin conductance responses (Gaigg et al., 2016). Alexithymia might be the main 477 contributor to emotion recognition impairments in autism (Cook et al., 2013; Oakley et al., 478 2016; Ola and Gullon-Scott, 2020). This hypothesis could also explain why enhanced 479 perceptual functioning lead to specific impairments in emotional face recognition in autism.

480 Additionally, it would explain the heterogeneity in emotion recognition in autistic individuals 481 (Cook et al., 2013). Thus, it would be of particular interest to include alexithymia scales in 482 research like ours in the future. However, this hypothesis would not explain similar 483 performances in autism and TD after BSF distractors in our experiment.

484 Alternatively, the sensitivity of autistic participants to filtered distractors could also 485 provide evidence to support predictive coding theories of autism (Brock, 2012; Sinha et al., 486 2014; Van de Cruys et al., 2014). The general predictive brain framework posits that the brain 487 is constantly generating top-down predictions about the sensory input (bottom-up), relying on 488 an internal model constructed from past experiences (Friston, 2010). Prediction error is the 489 difference between prediction and sensory input. The precision of prediction error can 490 determine the relative weight of top-down versus bottom up information (Friston, 2010) and 491 should be adjusted according to the context (relevance or not of predictive cues). This 492 adjustment might be difficult in autistic individuals and each prediction error might be seen as 
493

494

495

496

497

498

499

500

501

502

503

504

505

506

507

508

509

510

511

512

513

514

515

516

517

518

519

520

521

522

523

524

525

important (Van de Cruys et al., 2013). This hypothesis is supported by electrophysiological studies on Mismatch Negativity in autistic adults. The Mismatch Negativity paradigm is used to study brain reactions to an unexpected event occurring among regular events and can be seen as an electrophysiological signal of perceptual prediction errors (Stefanics et al., 2014). Autistic people often elicit atypical reactions to deviant stimuli in Mismatch paradigm (Gomot and Wicker, 2012). In our experiment, the second target appeared after a stream of distractors containing the same low-level characteristics (i.e., the same type of filtering was used for each distractor). It is reasonable to assume that participants became used to low-level characteristics of the distractors (at Lag 5 and 7) and made strong predictions for the next image, based on regularity. When distractors were low-pass or high-pass filtered, the appearance of the unfiltered second target T2 could violate the expectation generated by the statistical regularity of the stream (based on low level information) leading to prediction errors. The disruption of the statistical regularity of the stream may impact autistic participants more, which leads to impaired T2 accuracy. In other words, individuals with autism would struggle to disengage from their prior as they expect to see the same low-level information. The more effortful adaptation to the change in low-level features in T2 would prevent them to memorize the face, subsequently impairing their accuracy. By contrast, TD can more flexibly adapt the disruption of the statistical regularity and could stay concentrated on the task, without being disturbed by low-level changes. In the case of BSF distractors, targets and distractors had the same low-level content, generating no prediction error related to low-level characteristics of the stimuli (i.e., spatial frequencies filtering), which may explain the absence of between-group differences for BSF distractors. This Mismatch perspective on the task is supported by research showing MMN elicited by emotional faces among neutral faces of different actors (Astikainen et al., 2013), meaning that regularity can be extracted despite some variations in the standard stimuli. It is also supported by research showing MMN elicited by spatial frequency changes (Heslenfeld, 2003; Sulykos and Czigler, 2011). However, further research would be needed to investigate this idea.

Less importantly, T2 accuracy appear reduced in our experiment (i.e., $M=33.5 \%$ ) as compared to other experiments (where T2 accuracy range from approximately $60 \%$ to $90 \%$ ), even if they implied autistic participants (Gaigg and Bowler, 2009; Yerys et al., 2013). It could be surprising as an attenuation of the AB (i.e., better T2 accuracy) is usually observed when targets are emotional faces (De Jong et al., 2009; Maratos et al., 2008). However, the similarity between targets and distractors, which were all emotional faces in our task, can 
526 reduce salience of targets among distractors thus increasing the AB (Müsch et al., 2012;

527 Raymond et al., 1995; Yerys et al., 2013). In addition, the answer choice in our task was presumably harder as compared to other similar tasks and may affect performances. Indeed, our participants have to identify the T1 face between three happy faces (and the same for T2). Finding a target face among three faces, without answering by chance, is more difficult than a dichotomous yes/no answer on a question such as "Did you see a face?". Additionally, we gave the instruction not to answer by chance, giving the possibility to choose "I don't know". The general repartition of answers on T2 was the following: $38.6 \%$ "I don't know", $0.5 \%$ No answer, $33.5 \%$ correct answers and $27.4 \%$ incorrect answers. Thus, considering only the trials when participants answer (i.e., the participant has a slight to strong degree of certainty regarding his answer), participants chose the correct answer in more than 50\% (chance level at 33\%). To better account for the confidence of participants, it could be interesting to employ a method used in Eiserbeck and Abdel Rahman (2020) in future research instead of offering the possibility to answer "I don't know". They used an AB paradigm with faces using objective as well as subjective criterion (i.e., degree of certainty of the participant regarding T2) as an index of T2 detection (Eiserbeck and Abdel Rahman, 2020). Whereas correct T2 report with a "slight impression" was between $70 \%$ and $74 \%$ (which is in accordance to usual T2 accuracy in AB task), correct T2 report with a "strong impression" was between $33 \%$ and $36 \%$ (which is similar to T2 accuracy in our task).

The task difficulty probably impaired T1 recognition as well. Indeed, we observed apparent poorer T1 accuracy in our experiment with greater variability as compared to T1 accuracy usually observed in other experiments. T1 accuracy was similar in both group, in accordance with intact happy faces identification in autism (Uljarevic and Hamilton, 2013). A correlation exists between T1 accuracy and FSIQ, as well as between T1 and PIQ for both groups, which could be in line with previous studies showing that higher IQ can enhance emotion recognition in both TD and ASD participants (Jones et al., 2011; Wright et al., 2008).

552 Nevertheless, when we removed the few outliers in term of IQ performances (2 ASD and 2

553 TD participants), the correlations between T1 accuracy and FSIQ and PIQ were not

554 significant anymore, although T1 accuracy still not significantly differed between groups.

555 Correlation between FSIQ and T2 accuracy was not significant neither, which is congruent 556 with previous research (Colzato et al., 2007) and contrary to Gaigg \& Bowler (2009), we did 557 not find any correlation between VIQ and T2 accuracy in ASD (nor in TD), which can 558 probably be explained by the non-verbal nature of our task. Taken together, these findings 
support the fact that IQ variations among our subjects have not impaired our results. Finally, we found a significant negative correlation between accuracy (for T1 and for T2) and age in $\mathrm{TD}$, performances becoming weaker with age, but this is not found in ASD. AB performances tend to improve between 18 and 39 years old, and then to decline (Georgiou-Karistianis et al., 2007). Hence, the negative correlation could be at odds with the fact that only 9 TD participants are aged 39 and above. However, a fast decrease of performances after 39 might explain this result. Surprisingly, this decline is not observed in ASD participants despite they are a bit older than TD participants in our study (ASD age rank $=19-47$, median $=33.5$; TD age rank $=19-44$, median $=31.0$ ). Two hypotheses can be brought up. First, it may be related to high IQ of ASD participants as compared to TD in our study. Indeed, higher IQ is usually associated with less cognitive decline (Steffener and Stern, 2012). Second, ASD might also partially protect against a cognitive decline related to age (Lever and Geurts, 2015), which is yet to be determined.

\section{Limitations}

Our study has some limitations pertaining to participants. Firstly, autistic participants were adults, mainly late diagnosed and had very high intellectual abilities, thus representing a small subset of autistic adults. Hence, our results cannot be generalized to the whole spectrum. Secondly, there is a high variability in performances of autistic participants, probably reflecting the highly heterogeneous autism spectrum or some other aspects such as, the degree of alexithymia. Data driven analysis might be conducted to distinguish autistic subgroups (see Latinus et al., 2019), but would require larger sample size. Thirdly, the correlation found with age could potentially have a slight impact on the result and should conduct to lower the maximal age in further studies. Finally, we were not able to collect ADOS data from all participants (we collected ADOS scores of 19 participants) although it would have been interesting to study correlation between these scores and performances in addition to the AQ, as the later have sometimes weak correlation with ADOS (Ashwood et al., 2016).

There is another limitation pertaining to the experiment. Our experiment included happy targets only because it has been suggested that people, even with autism, can recognize happy emotion easily. This selection was intentional to focus on low level visual processing, which is the main research hypothesis. Further studies need to determine if the effect of spatial 
591 frequencies reported here is specific to happy faces, or could be observed with other

592 emotional facial expression, with non-social stimuli (e.g. International Affective Picture

593 System) and non-emotional stimuli (e.g. gender, objects, natural scenes).

594

\section{Conclusion}

596 The present study shed light on the influence of spatial frequencies on visual

597 consciousness in both autistic and TD individuals. The results of the study extend our

598 understanding of the attentional blink phenomenon and of the role of spatial frequencies

599 information for visual consciousness of emotional faces. Our findings suggest that bottom-up

600 HSF information is probably more important for exogenous consciousness for TD

601 participants, and even more in autism, compared to top-down LSF information provided by

602 the orbitofrontal cortex Additionally, our findings suggest that visual consciousness in autism

603 rely also on LSF. It could indicate increased sensitivity to low-level visual characteristics in

604 autism and be in accordance with the Enhanced Perceptual Functioning framework, an

605 influential model of autism. Our results could be also explained by predictive coding

606 frameworks, which are emerging models for explaining autism characteristics. However,

607 further studies are required to tease apart low-level processing from predictive coding

608 processing in autism. Results of the current research could have implications for our

609 understanding of atypical visual processing in autism, which can partly contribute to social

610 deficits.

612 List of abbreviations

613

614

615 ASD $=$ Autism Spectrum Disorder

$616 \quad \mathrm{BSF}=$ Broad Spatial Frequencies

$617 \mathrm{cpd}=$ cycle per degree

618 DSM = Diagnostic and Statistical of Mental Disorder

$619 \quad$ FSIQ $=$ Full Scale Intelligence Quotient 
$620 \quad \mathrm{HSF}=$ High Spatial Frequencies

$621 \mathrm{IQ}=$ Intelligence Quotient

$622 \quad$ LSF $=$ Low Spatial Frequencies

$623 \mathrm{~ms}=$ milliseconds

624 PIQ = Performance Intelligence Quotient

625 TD = Typically Developing

626 VIQ = Verbal Intelligence Quotient

$627 \quad$ WAIS $=$ Wechsler Adult Intelligence Scale

628 WISC $=$ Wechsler Intelligence Scale for Children

629

630 Acknowledgments

631 We thank all participants and their families for their help in this study. We also thank the

632 Expertise Center for Asperger of Grenoble, the Savoyard Center for Autism Evaluation, Nelly

633 Coroir and Jérôme Ecochard for their help with volunteer recruitment. Finally, we thank Eric

634 Guinet for his invaluable assistance with screen tests and calibration.

635 Disclosure statement

636 The authors declare that they have no competing interests.

637 Data availability statement

638 The datasets generated and/or analyzed during the current study are available in the Open

639 Science Framework repository

640 https://osf.io/maqvz/?view only=3002780bdf8247ecb3669e9870b4c00d. E-prime experiment 641 and stimuli are available in the following repository: https://osf.io/n4svb/. Any other materials 642 are available from the corresponding author on reasonable request.

643 Ethics approval and consent to participate

644 Written informed consent was obtained from all individual participants included in the study. 645 All procedures performed in this study involving human participants were in accordance with 646 the Code of Ethics of the World Medical Association (Declaration of Helsinki) and approved 
647 by the local ethics committee (CER-Grenoble Alps, COMUE University Grenoble Alpes,

648 IRB00010290).

$649 \quad$ Funding

650 This study was supported by the French Ministry of Higher Education, Research and

651 Innovation (France) to Adeline Lacroix and by the Pole Grenoble Cognition. This work has

652 been partially supported by MIAI@Grenoble Alpes, (ANR-19-P3IA-0003)

\section{Author's contribution}

654 AL collected, analyzed, interpreted the data, and wrote the manuscript. MG and MM were 655 major contributors to data interpretation and writing of the manuscript. MF largely 656 contributed to data collection. MP and MM conceived the experiment. GP, CP, NV, MP and

657 FD contributed in data interpretation and substantively revised the manuscript. All authors 658 provided approval for publication of the content.

659

660

References

661 Amador-Campos, J.A., Aznar-Casanova, J.A., Bezerra, I., Torro-Alves, N., Sánchez, M.M., 662 Amador-Campos, J.A., Aznar-Casanova, J.A., Bezerra, I., Torro-Alves, N., Sánchez, M.M., 2015. Attentional blink in children with attention deficit hyperactivity disorder.

664 Brazilian Journal of Psychiatry 37, 133-138. https://doi.org/10.1590/1516-4446-20141415

American Psychiatric Association, 2013. Diagnostic and Statistical Manual of Mental Disorders, 5th Edition: DSM-5, 5 edition. ed. American Psychiatric Publishing.

American Psychiatric Association, 2003. DSM-IV-TR Manuel diagnostique et statistique des troubles mentaux : Texte révisié, 2e ed. Editions Masson, Issy-les-Moulineaux.

Amirault, M., Etchegoyhen, K., Delord, S., Mendizabal, S., Kraushaar, C., Hesling, I., Allard, M., Bouvard, M., Mayo, W., 2009. Alteration of Attentional Blink in High Functioning Autism: A Pilot Study. J Autism Dev Disord 39, 1522-1528. 
674 Ashwood, K., Gillan, N., Horder, J., Hayward, H., Woodhouse, E., McEwen, F., Findon, J.,

675

676

677

678

679

680

681

682

683

684

685

686

687

688

689

690

691

692

693

694

695

696

697

698 Eklund, H., Spain, D., Wilson, C.E., Cadman, T., Young, S., Stoencheva, V., Murphy, C., Robertson, D., Charman, T., Bolton, P., Glaser, K., Asherson, P., Murphy, D., 2016. Predicting the diagnosis of autism in adults using the Autism-Spectrum Quotient (AQ) questionnaire. Psychological Medicine 1 1-10. https://doi.org/10.1017/S0033291716001082

Astikainen, P., Cong, F., Ristaniemi, T., Hietanen, J., 2013. Event-related potentials to unattended changes in facial expressions: detection of regularity violations or encoding of emotions? Front. Hum. Neurosci. 7. https://doi.org/10.3389/fnhum.2013.00557

Balas, B., Momsen, J.L., 2014. Attention "Blinks" Differently for Plants and Animals. LSE 13, 437-443. https://doi.org/10.1187/cbe.14-05-0080

Balas, B., Verdugo, M.Q., 2018. Low-level orientation information for social evaluation in face images. Psychon Bull Rev 25, 2224-2230. https://doi.org/10.3758/s13423-018-1438-5

Baron-Cohen, S., Wheelwright, S., Skinner, R., Martin, J., Clubley, E., 2001. The AutismSpectrum Quotient (AQ): Evidence from Asperger Syndrome/High-Functioning Autism, Malesand Females, Scientists and Mathematicians. J Autism Dev Disord 31, 5-17. https://doi.org/10.1023/A:1005653411471

Bishop, S.L., Seltzer, M.M., 2012. Self-Reported Autism Symptoms in Adults with Autism Spectrum Disorders. J Autism Dev Disord 42, 2354-2363. https://doi.org/10.1007/s10803-012-1483-2

Brock, J., 2012. Alternative Bayesian accounts of autistic perception: comment on Pellicano and Burr. Trends in Cognitive Sciences 16, 573-574. https://doi.org/10.1016/j.tics.2012.10.005

Calvo, M.G., Nummenmaa, L., 2016. Perceptual and affective mechanisms in facial expression recognition: An integrative review. Cognition and Emotion 30, 1081-1106. 

https://doi.org/10.1080/02699931.2015.1049124

700

701

702

703

704

705

706

707

708

709

710

711

712

Caplette, L., Wicker, B., Gosselin, F., 2016. Atypical Time Course of Object Recognition in Autism Spectrum Disorder. Scientific Reports 6, 35494. https://doi.org/10.1038/srep35494

Colzato, L.S., Spapé, M.M.A., Pannebakker, M.M., Hommel, B., 2007. Working memory and the attentional blink: Blink size is predicted by individual differences in operation span. Psychonomic Bulletin \& Review 14, 1051-1057. https://doi.org/10.3758/BF03193090

Cook, R., Brewer, R., Shah, P., Bird, G., 2013. Alexithymia, Not Autism, Predicts Poor Recognition of Emotional Facial Expressions. Psychol Sci 24, 723-732. https://doi.org/10.1177/0956797612463582

Corradi-Dell'Acqua, C., Schwartz, S., Meaux, E., Hubert, B., Vuilleumier, P., Deruelle, C., 2014. Neural responses to emotional expression information in high- and low-spatial frequency in autism: evidence for a cortical dysfunction. Front. Hum. Neurosci. 8. https://doi.org/10.3389/fnhum.2014.00189

Dawson, G., Webb, S.J., McPartland, J., 2005. Understanding the Nature of Face Processing Impairment in Autism: Insights From Behavioral and Electrophysiological Studies. Developmental Neuropsychology

27, $403-424$. https://doi.org/10.1207/s15326942dn2703_6

De Gardelle, V., Kouider, S., 2010. How Spatial Frequencies and Visual Awareness Interact During Face Processing. Psychological Science 21, 58-66. https://doi.org/10.1177/0956797609354064

De Jong, P.J., Koster, E.H.W., van Wees, R., Martens, S., 2009. Emotional facial expressions and the attentional blink: Attenuated blink for angry and happy faces irrespective of social anxiety. Cognition and Emotion 23, 1640-1652. https://doi.org/10.1080/02699930802490227 
724 Deruelle, C., Rondan, C., Gepner, B., Tardif, C., 2004. Spatial Frequency and Face Processing in Children with Autism and Asperger Syndrome. J Autism Dev Disord 34, 199-210. https://doi.org/10.1023/B:JADD.0000022610.09668.4c

Deruelle, C., Rondan, C., Salle-Collemiche, X., Bastard-Rosset, D., Da Fonséca, D., 2008. Attention to low- and high-spatial frequencies in categorizing facial identities, emotions and gender in children with autism. Brain and Cognition 66, 115-123. https://doi.org/10.1016/j.bandc.2007.06.001

Eiserbeck, A., Abdel Rahman, R., 2020. Visual consciousness of faces in the attentional blink: Knowledge-based effects of trustworthiness dominate over appearance-based $\begin{array}{lllll}\text { impressions. Consciousness } & \text { and }\end{array}$ https://doi.org/10.1016/j.concog.2020.102977

Elliott, J.C., Giesbrecht, B., 2010. Perceptual load modulates the processing of distractors presented at task-irrelevant locations during the attentional blink. Attention, Perception, \& Psychophysics 72, 2106-2114. https://doi.org/10.3758/BF03196687

Friston, K., 2010. The free-energy principle: a unified brain theory? Nature Reviews Neuroscience 11, 127-138. https://doi.org/10.1038/nrn2787

Gaigg, S.B., Bowler, D.M., 2009. Brief Report: Attenuated Emotional Suppression of the Attentional Blink in Autism Spectrum Disorder: Another Non-Social Abnormality? J Autism Dev Disord 39, 1211-1217. https://doi.org/10.1007/s10803-009-0719-2

Gaigg, S.B., Cornell, A.S., Bird, G., 2016. The psychophysiological mechanisms of alexithymia in autism spectrum disorder: Autism. https://doi.org/10.1177/1362361316667062

Georgiou-Karistianis, N., Tang, J., Vardy, Y., Sheppard, D., Evans, N., Wilson, M., Gardner, B., Farrow, M., Bradshaw, J., 2007. Progressive age-related changes in the attentional blink paradigm. Neuropsychol Dev Cogn B Aging Neuropsychol Cogn 14, 213-226. https://doi.org/10.1080/13825580500320681 
749 Golarai, G., Grill-Spector, K., Reiss, A.L., 2006. Autism and the development of face processing. Clin Neurosci Res 6, 145-160. https://doi.org/10.1016/j.cnr.2006.08.001

Gomot, M., Wicker, B., 2012. A challenging, unpredictable world for people with Autism Spectrum Disorder. International Journal of Psychophysiology, Predictive information processing in the brain: Principles, neural mechanisms and models 83, 240-247. https://doi.org/10.1016/j.ijpsycho.2011.09.017

Grégoire, J., Wierzbicki, C., 2009. Comparaison de quatre formes abrégées de l'échelle d'intelligence de Wechsler pour adultes - troisième édition (WAIS-III). Revue Européenne de Psychologie Appliquée/European Review of Applied Psychology 59, 17-24. https://doi.org/10.1016/j.erap.2007.08.003

Harms, M.B., Martin, A., Wallace, G.L., 2010. Facial Emotion Recognition in Autism Spectrum Disorders: A Review of Behavioral and Neuroimaging Studies. Neuropsychol Rev 20, 290-322. https://doi.org/10.1007/s11065-010-9138-6

Heslenfeld, D.J., 2003. Visual Mismatch Negativity, in: Polich, J. (Ed.), Detection of Change: Event-Related Potential and FMRI Findings. Springer US, Boston, MA, pp. 41-59. https://doi.org/10.1007/978-1-4615-0294-4_3

Iidaka, T., Yamashita, K., Kashikura, K., Yonekura, Y., 2004. Spatial frequency of visual image modulates neural responses in the temporo-occipital lobe. An investigation with eventrelated fMRI. Brain Res Cogn Brain Res 18, 196-204. https://doi.org/10.1016/j.cogbrainres.2003.10.005

Jemel, B., Mottron, L., Dawson, M., 2006. Impaired Face Processing in Autism: Fact or Artifact? J Autism Dev Disord 36, 91-106. https://doi.org/10.1007/s10803-005-0050-5

Jones, C.R.G., Pickles, A., Falcaro, M., Marsden, A.J.S., Happé, F., Scott, S.K., Sauter, D., Tregay, J., Phillips, R.J., Baird, G., Simonoff, E., Charman, T., 2011. A multimodal approach to emotion recognition ability in autism spectrum disorders. Journal of Child 
Psychology and Psychiatry 52, 275-285. https://doi.org/10.1111/j.14697610.2010.02328.x

Kauffmann, L., Chauvin, A., Pichat, C., Peyrin, C., 2015. Effective connectivity in the neural network underlying coarse-to-fine categorization of visual scenes. A dynamic causal modeling study. Brain and Cognition 99, 46-56. https://doi.org/10.1016/j.bandc.2015.07.004

Kéïta, L., Guy, J., Berthiaume, C., Mottron, L., Bertone, A., 2014. An early origin for detailed perception in Autism Spectrum Disorder: biased sensitivity for high-spatial frequency information. Scientific Reports 4, 5475. https://doi.org/10.1038/srep05475

Kinnaird, E., Stewart, C., Tchanturia, K., 2019. Investigating alexithymia in autism: A systematic review and meta-analysis. European Psychiatry 55, 80-89. https://doi.org/10.1016/j.eurpsy.2018.09.004

Latinus, M., Mofid, Y., Kovarski, K., Charpentier, J., Batty, M., Bonnet-Brilhault, F., 2019. Atypical Sound Perception in ASD Explained by Inter-Trial (In)consistency in EEG. Front. Psychol. 10. https://doi.org/10.3389/fpsyg.2019.01177

Lever, A., Geurts, H., 2015. Age-related differences in cognition across the adult lifespan in autism spectrum disorder. Autism research : official journal of the International Society for Autism Research 9. https://doi.org/10.1002/aur.1545

Lord, C., Rutter, M., Couteur, A.L., 1994. Autism Diagnostic Interview-Revised: A revised version of a diagnostic interview for caregivers of individuals with possible pervasive developmental disorders. J Autism Dev Disord 24, 659-685. https://doi.org/10.1007/BF02172145

Lord, C., Rutter, M., Goode, S., Heemsbergen, J., Jordan, H., Mawhood, L., Schopler, E., 1989. Austism diagnostic observation schedule: A standardized observation of communicative and social behavior. J Autism Dev Disord 19, 185-212. 
https://doi.org/10.1007/BF02211841

800

801

802

803

804

805

806

807

808

809

810

811

812

813

814

815

816

817

818

819

820

821

822

823

Ma, D.S., Correll, J., Wittenbrink, B., 2015. The Chicago face database: A free stimulus set of faces and norming data. Behav Res 47, 1122-1135. https://doi.org/10.3758/s13428$014-0532-5$

Maratos, F.A., Mogg, K., Bradley, B.P., 2008. Identification of angry faces in the attentional blink. Cognition \& Emotion 22, 1340-1352. https://doi.org/10.1080/02699930701774218

Mathis, K.I., Wynn, J.K., Breitmeyer, B., Nuechterlein, K.H., Green, M.F., 2011. The Attentional Blink in Schizophrenia: Isolating the Perception/Attention Interface. J Psychiatr Res 45, 1346-1351. https://doi.org/10.1016/j.jpsychires.2011.04.002

Mottron, L., Dawson, M., Soulières, I., Hubert, B., Burack, J., 2006. Enhanced Perceptual Functioning in Autism: An Update, and Eight Principles of Autistic Perception. J Autism Dev Disord 36, 27-43. https://doi.org/10.1007/s10803-005-0040-7

Müsch, K., Engel, A.K., Schneider, T.R., 2012. On the Blink: The Importance of TargetDistractor Similarity in Eliciting an Attentional Blink with Faces. PLOS ONE 7, e41257. https://doi.org/10.1371/journal.pone.0041257

Navajas, J., Ahmadi, M., Quiroga, R.Q., 2013. Uncovering the Mechanisms of Conscious Face Perception: A Single-Trial Study of the N170 Responses. J. Neurosci. 33, 1337-1343. https://doi.org/10.1523/JNEUROSCI.1226-12.2013

Oakley, B.F.M., Brewer, R., Bird, G., Catmur, C., 2016. Theory of Mind Is Not Theory of Emotion: A Cautionary Note on the Reading the Mind in the Eyes Test. J Abnorm Psychol 125, 818-823. https://doi.org/10.1037/abn0000182

Ola, L., Gullon-Scott, F., 2020. Facial emotion recognition in autistic adult females correlates with alexithymia, not autism. Autism 24, 2021-2034. https://doi.org/10.1177/1362361320932727 
824 Olivers, C., Meeter, M., 2008. A Boost and Bounce Theory of Temporal Attention. Psychological review 115, 836-63. https://doi.org/10.1037/a0013395

826

827

828

829

830

831

832

833

834

835

836

837

838

839

840

841

842

843

844

845

846

847

848

OMS, Collectif, 1992. CIM-10/ICD-10 : Descriptions cliniques et directives pour le diagnostic. Editions Masson.

Oruc, I., Balas, B., Landy, M.S., 2019. Face perception: A brief journey through recent discoveries and current directions. Vision Res 157, 1-9. https://doi.org/10.1016/j.visres.2019.06.005

Oruc, I., Shafai, F., Iarocci, G., 2018. Link Between Facial Identity and Expression Abilities Suggestive of Origins of Face Impairments in Autism: Support for the SocialMotivation Hypothesis:

Psychological

Science. https://doi.org/10.1177/0956797618795471

Park, G., Van Bavel, J.J., Vasey, M.W., Egan, E.J.L., Thayer, J.F., 2012. From the heart to the mind's eye: Cardiac vagal tone is related to visual perception of fearful faces at high spatial frequency. Biological Psychology 90, 171-178. https://doi.org/10.1016/j.biopsycho.2012.02.012

Plant, E.A., Kling, K.C., Smith, G.L., 2004. The Influence of Gender and Social Role on the Interpretation of Facial Expressions. Sex Roles 51, 187-196. https://doi.org/10.1023/B:SERS.0000037762.10349.13

Quiroga, R.Q., Mukamel, R., Isham, E.A., Malach, R., Fried, I., 2008. Human single-neuron responses at the threshold of conscious recognition. PNAS 105, 3599-3604. https://doi.org/10.1073/pnas.0707043105

R Core Team, 2019. R: A language and environment for statistical computing. 2013.

Raymond, J.E., Shapiro, K.L., Arnell, K.M., 1995. Similarity determines the attentional blink. J Exp Psychol Hum Percept Perform 21, 653-662.

Rinehart, N., Tonge, B., Brereton, A., Bradshaw, J., 2010. Attentional blink in young people 

with high-functioning autism and Asperger's disorder. Autism 14, 47-66. https://doi.org/10.1177/1362361309335718

Schyns, P.G., Oliva, A., 1994. From Blobs to Boundary Edges: Evidence for Time- and SpatialScale-Dependent Scene Recognition. Psychol Sci 5, 195-200. https://doi.org/10.1111/j.1467-9280.1994.tb00500.x

Sergent, C., Baillet, S., Dehaene, S., 2005. Timing of the brain events underlying access to consciousness during the attentional blink. Nat Neurosci 8, 1391-1400. https://doi.org/10.1038/nn1549

Shapiro, K.L., Raymond, J.E., Arnell, K.M., 1997. The attentional blink. Trends in Cognitive Sciences 1, 291-296. https://doi.org/10.1016/S1364-6613(97)01094-2

Shore, D.I., McLaughlin, E.N., Klein, R.M., 2001. Modulation of the attentional blink by differential resource allocation. Canadian Journal of Experimental Psychology/Revue canadienne de psychologie expérimentale 55, 318-324. https://doi.org/10.1037/h0087379

Sinha, P., Kjelgaard, M.M., Gandhi, T.K., Tsourides, K., Cardinaux, A.L., Pantazis, D., Diamond, S.P., Held, R.M., 2014. Autism as a disorder of prediction. PNAS 111, 15220-15225. https://doi.org/10.1073/pnas.1416797111

Skottun, B.C., 2015. On the use of spatial frequency to isolate contributions from the magnocellular and parvocellular systems and the dorsal and ventral cortical streams. Neuroscience \& Biobehavioral Reviews 56, 266-275. https://doi.org/10.1016/j.neubiorev.2015.07.002

Stefanics, G., Kremláček, J., Czigler, I., 2014. Visual mismatch negativity: a predictive coding view. Front. Hum. Neurosci. 8. https://doi.org/10.3389/fnhum.2014.00666

Steffener, J., Stern, Y., 2012. Exploring the neural basis of cognitive reserve in aging. Biochimica et Biophysica Acta (BBA) - Molecular Basis of Disease, Imaging Brain 
874

875

876

877

878

879

880

881

882

883

884

885

886

887

888

889

890

891

892

893

894

895

896

897

898

Aging and Neurodegenerative

Disease

1822

467-473. https://doi.org/10.1016/j.bbadis.2011.09.012

Sulykos, I., Czigler, I., 2011. One plus one is less than two: Visual features elicit non-additive mismatch-related brain activity. Brain Research 1398, 64-71. https://doi.org/10.1016/j.brainres.2011.05.009

Tanaka, J.W., 2001. The entry point of face recognition: Evidence for face expertise. Journal of Experimental Psychology: General 130, 534-543. https://doi.org/10.1037/00963445.130 .3 .534

Tang, J., Falkmer, M., Horlin, C., Tan, T., Vaz, S., Falkmer, T., 2015. Face Recognition and Visual Search Strategies in Autism Spectrum Disorders: Amending and Extending a Recent Review by Weigelt et al. PLOS ONE 10, e0134439. https://doi.org/10.1371/journal.pone.0134439

Uljarevic, M., Hamilton, A., 2013. Recognition of Emotions in Autism: A Formal MetaAnalysis. J Autism Dev Disord 43, 1517-1526. https://doi.org/10.1007/s10803-0121695-5

Van de Cruys, S., de-Wit, L., Evers, K., Boets, B., Wagemans, J., 2013. Weak Priors versus Overfitting of Predictions in Autism: Reply to Pellicano and Burr (TICS, 2012). iPerception 4, 95-97. https://doi.org/10.1068/i0580ic

Van de Cruys, S., Evers, K., Van der Hallen, R., Van Eylen, L., Boets, B., De-Wit, L., Wagemans, J., 2014. Precise minds in uncertain worlds: predictive coding in autism. Psychological Review 649-675.

Villepoux, A., Vermeulen, N., Niedenthal, P., Mermillod, M., 2015. Evidence of fast and automatic gender bias in affective priming. Journal of Cognitive Psychology 27, 301309. https://doi.org/10.1080/20445911.2014.1000919

Visser, T.A.W., Bischof, W.F., Di Lollo, V., 2004. Rapid serial visual distraction: Task- 
899

900

901

902

903

904

905

906

907

908

909

910

911

912

913

914

915

916

917

918

919

920

irrelevant items can produce an attentional blink. Perception \& Psychophysics 66, 1418-1432. https://doi.org/10.3758/BF03195008

Vuilleumier, P., Armony, J.L., Driver, J., Dolan, R.J., 2003. Distinct spatial frequency sensitivities for processing faces and emotional expressions. Nature Neuroscience 6, 624-631. https://doi.org/10.1038/nn1057

Wechsler, D., 2008. Wechsler Adult Intelligence Scale_-Fourth Edition (WAIS-IV) [WWW Document].

URL https://scholar.googleusercontent.com/scholar?q=cache:VlcK12BcQ6kJ:scholar.googl e.com $/ \& h l=f r \& a s \_s d t=0,5($ accessed 12.11 .18$)$.

Wechsler, D., 2003. Wechsler intelligence scale for children-WISC-IV. Psychological Corporation.

Wechsler, D., 1997. WAIS-III, Wechsler adult intelligence scale: Administration and scoring manual. Psychological Corporation.

Wright, B., Clarke, N., Jordan, J., Young, A.W., Clarke, P., Miles, J., Nation, K., Clarke, L., Williams, C., 2008. Emotion recognition in faces and the use of visual context in young people with high-functioning autism spectrum disorders. Autism 12, 607-626. https://doi.org/10.1177/1362361308097118

Yerys, B.E., Ruiz, E., Strang, J., Sokoloff, J., Kenworthy, L., Vaidya, C.J., 2013. Modulation of attentional blink with emotional faces in typical development and in autism spectrum disorders. Journal of Child Psychology and Psychiatry 54, 636-643. https://doi.org/10.1111/jcpp.12013 